Indra Waspada

\title{
ANALISA BEST PRACTICE SERVICE LEVEL MANAGEMENT (SLM) CISCO MENGGUNAKAN KRITERIA KELENGKAPAN DARI THOMAS SCHAAF
}

\author{
Indra Waspada \\ Universitas Diponegoro \\ indrawaspada@undip.ac.id
}

\begin{abstract}
Service Level Agreement (SLA) is an important document to facilitate IT service provisioning by clearly defined Quality of Service (QoS) parameters. The management of SLA is the main subject in the discipline of Service Level Management (SLM). SLM is very important to improve relationship between IT service provider and its customer. It delivers documented agreement as a common understanding of expectation and possible achievements to the agreed cost. It means SLM builds the interface between an IT organization and its customer, so it plays a critical and important role in the context of IT service management.

In this paper, an SLM best practice from CISCO will be analyzed with the assessment criteria of SLM framework by Thomas Schaaf. The result will be followed with several suggestion to fulfil the gap in this CISCO's best practice.
\end{abstract}

Keywords : Framework, best practice, Service Level Management, IT service management

\section{Pendahuluan}

Dalam konteks pengelolaan layanan Teknologi Informasi atau lebih dikenal dengan Information Technology Service Management (ITSM), Service level Management (SLM) merupakan salah satu proses vital yang memiliki peran utama sebagai sarana penghubung antara penyedia layanan TI dengan pelanggan dan penggunanya dalam mencapai kesepakatan tingkat layanan baik berupa kontrak maupun pelaksanaannya

Menurut pengamatan Thomas Schaaf [7], beberapa tahun belakangan ini berbagai konsep untuk membangun SLM yang efektif banyak berkembang melalui penelitian dan praktek. Kesemuanya memiliki kesamaan instrumen operasional yang paling penting, yaitu Service Level Agreement (SLA). Namun kenyataannya pendekatan-pendekatan yang dilakukan saling berbeda tergantung pada cakupan dan kedalaman pembahasan, kesesuaian dengan dukungan teknis dan perangkat, atau pada target audien nya.

Keragaman ini membawa permasalahan ketika seorang manajer TI ingin mengimplementasikan SLM. Di satu sisi masih belum ada pendekatan yang menyeluruh, dan di lain pihak, keberadaan konsep, kerangka kerja, dan teknologi masih seperti pecahan puzzle yang belum terangkai.

Menjawab permasalahan tersebut, Schaaf mengusulkan kriteria penilaian untuk kerangka kerja SLM yang harus dapat melengkapi tiga aspek berikut: aspek manajemen, aspek SLA dan QoS, serta aspek umum.

Dengan kriteria penilaiannya tersebut, Schaaf telah melakukan perbandingan antara dua kerangka kerja SLM penting yaitu proses SLM pada IT infrastructure Library (ITIL) dan SLA Management Handbook dari NGOSS (sekarang bernama frameworx) [7].

Dengan menggunakan metode dan teknik penelitian yang sama, kali ini akan dilakukan analisa terhadap pendekatan SLM dari CISCO. Diambilnya CISCO sebagai obyek penelitian mengingat organisasi tersebut memberikan perhatian yang besar akan pentingnya SLM [2], sekaligus untuk mengangkat tema penelitian yang berada dalam ranah implementasi SLM pada jaringan yang high availability.

\section{Best Practice SIm Dari Cisco}

Sebagai vendor penyedia perangkat jaringan terbesar di dunia, CISCO menyadari bahwa saat ini teknologi informasi menjadi kesatuan dengan bisnis sehingga perangkat yang dikembangkan 
oleh CISCO juga harus menyesuaikan dengan basis kebutuhan tersebut.

Agar implementasi SLM dapat optimal maka produk yang dihasilkan oleh CISCO harus dapat diukur, dikelola dan dipantau pencapaiannya. Karena itu melalui best practice SLM nya, CISCO memberikan panduan untuk mengimplementasikan SLM dalam konteks jaringan yang high-availability [3].

Suatu best practice adalah formula dan prosedur yang telah dibuktikan kesuksesannya dalam praktik (dunia nyata), umumnya berupa saran, petunjuk, dan contoh-contoh. Sehingga implementasinya di lapangan membutuhkan adaptasi, misalnya oleh manajer SLM, untuk menyesuaikan dengan situasi dan kondisi lapangan.

Dalam penelitian ini, kajian dilakukan terhadap white paper dari CISCO yang berjudul: CISCO, "Service Level Management: Best practice White Paper" [3] kemudian panduan tersebut akan dibandingkan dengan kriteria kelengkapan kerangka kerja SLM yang diberikan oleh Thomas Schaaf.

Untuk memberi gambaran umum terhadap isi panduan dari CISCO tersebut maka pada dua sub bab berikut ini akan disajikan ulasannya.

\subsection{Tahapan Implementasi SLM}

Pada tahap implementasi SLM, CISCO memberi gambaran dan panduan nya melalui enam belas tahap seperti yang ditampilkan pada gambar 1. Tahapan tersebut terbagi dalam dua kategori utama, yang diperjelas dalam sub kategorinya secara detil sebagai berikut :

a. Pendefinisian tingkat layanan jaringan.

Pendefinisian tingkat layanan merupakan langkah yang sangat penting dalam mencapai QOS yang konsisten bagi organisasi dan membantu menjaga availability. CISCO menyarankan enam langkah berikut ini dalam membangun dan mendukung suatu model tingkat layanan.

1. Menganalisis target teknis dan kendalanya

2. Pendefinisian rancangan availability jaringan

3. Membuat profil aplikasi-aplikasi kritis yang digunakan pelanggan.
4. Pendefinisian standar-standar availability dan performa

5. Membuat definisi dasar tingkat layanan

6. Menyusun metrik dan rancangan pemantauan
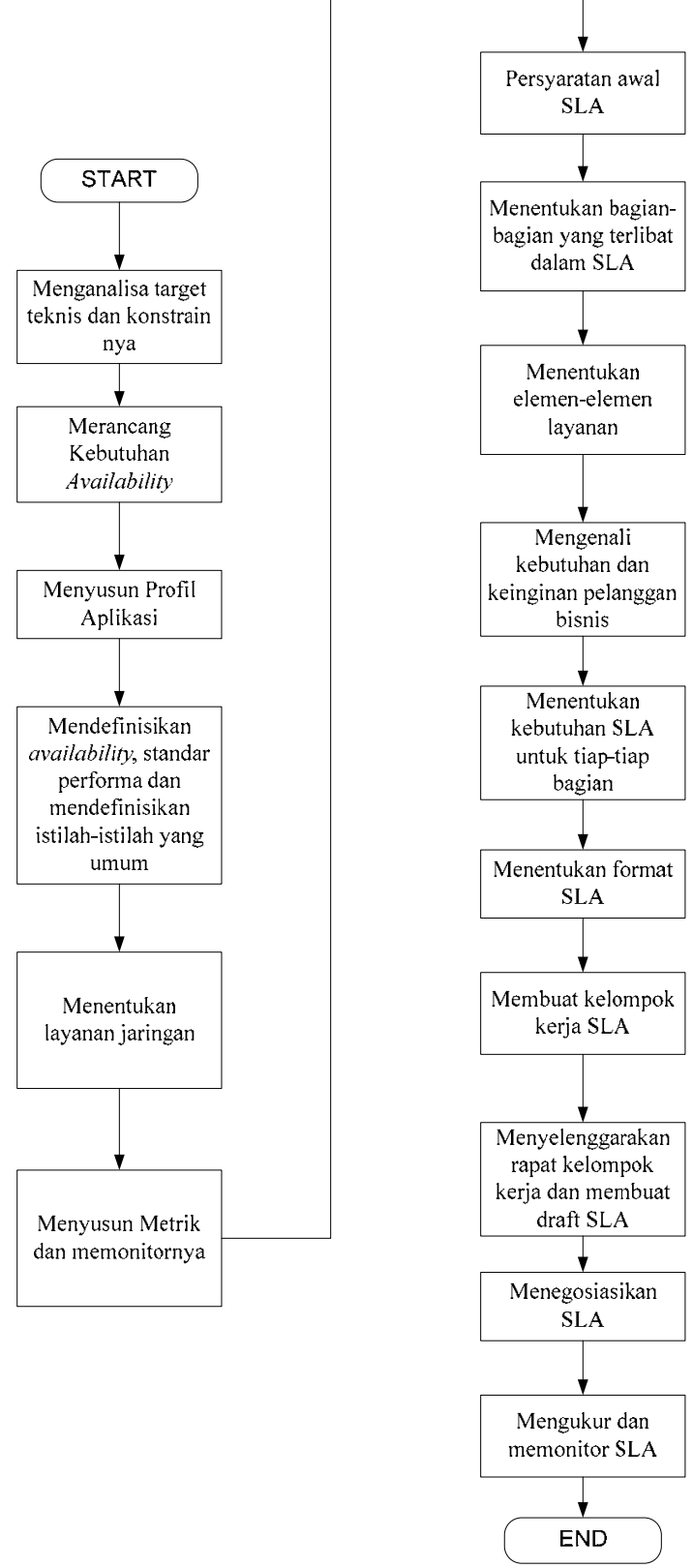

Gambar 1. Tahap implementasi SLM menurut CISCO 
b. Penyusunan dan pengelolaan SLA

Langkah berikutnya memberi perbaikanperbaikan terhadap tahap pendefinisian tingkat layanan, untuk menyatukan sasaran bisnis dan kebutuhan biaya dengan kualitas layanan. Berikut ini langkah-langkah yang dimaksudkan:

1. Memenuhi persyaratan awal SLA.

2. Menentukan bagian-bagian yang terlibat dalam SLA

3. Menentukan elemen-elemen layanan

4. Memahami kebutuhan dan target pelanggan bisnis

5. Mendefinisikan SLA yang dibutuhkan oleh masing-masing bagian.

6. Menentukan format SLA

7. Membentuk kelompok kerja SLA

8. Mengadakan rapat kelompok kerja dan menyusun draft SLA

9. Menegosiasikan SLA

10. Melakukan pengukuran dan pemantauan kesesuaian SLA.

\subsection{Indikator Performa SLM}

Menurut CISCO, indikator performa SLM memberi suatu mekanisme untuk memonitor dan memperbaiki tingkat layanan sebagai tolok ukur kesuksesan. Mekanisme ini menjadikan organisasi lebih cepat dalam bereaksi menangani permasalahan dan akan lebih mudah mengenali isu yang mempengaruhi layanan. Mengabaikan pengukuran terhadap tingkat layanan sama artinya dengan meninggalkan segala rancangan proaktif yang telah dibuat karena organisasi dipaksa berada dalam kondisi reaktif. Tidak ada yang akan berkata layanan yang diberikan sudah bagus, justru akan banyak pengguna yang mengeluhkan layanan tidak seperti yang diharapkan.

Tiga panduan dari CISCO dalam menyusun indikator terhadap performa SLA adalah:

a. Pendokumentasian definisi tingkat layanan atau SLA yang mencakup availability, performa, waktu respon layanan secara reaktif, target resolusi permasalahan, dan eskalasi permasalahan.

b. Metrik indikator performa, mencakup availability, performa, waktu respon layanan berdasarkan prioritas, waktu untuk menyelesaikan berdasarkan prioritas, dan parameter-parameter SLA lainnya yang dapat diukur.

c. Rapat mingguan manajemen tingkat layanan jaringan untuk mengkaji kesesuaian tingkat layanan serta mengimplementasikan perbaikan

\section{Kriteria Penilaian Kelengkapan Kerangka Kerja SIm Menurut Thomas Schaaf}

Thomas Schaaf memberikan kriteria penilaian kelengkapan kerangka kerja SLM mencakup tiga aspek sebagai berikut [7]:

\subsection{Aspek Manajemen}

a. Proses manajemen

Berdasarkan prinsip orientasi pada proses, aktivitas manajemen SLA yang efektif harus saling terkait dalam suatu proses manajemen. Proses manajemen dikenali melalui aktifitas sequensial yang jelas disertai gambaran tanggung jawab untuk setiap langkah atau aktivitas tersebut. Kerangka kerja harus menspesifikasikan proses SLM, aktivitas, tanggung jawab, serta proses masukan dan keluarannya.

b. Hubungan dan ketergantungan dengan disiplin manajemen yang lain.

SLM bukanlah suatu fungsi manajemen yang berdiri sendiri, melainkan saling terkait dengan fungsi yang lain. Karena itu kerangka kerja SLM harus memperhatikan pengelolaan dalam lingkup manajemen serta sebaik mungkin menjelaskan antar-muka nya dalam berkomunikasi.

c. Panduan penilaian manajemen

Proses, perangkat, dan rekomendasi yang diberikan harus dapat dinilai dan diukur. Oleh karena itu, kerangka kerja harus memberikan panduan yang konkrit mengenai bagaimana mengevaluasi implementasinya. Biasanya menggunakan Critical Success Factors (CSF) dan Key Performance Indicators (KPI).

d. Keselarasan SLM dengan bisnis

Kerangka kerja SLM dapat dikatakan telah selaras dengan bisnis bila keputusankeputusan penting selalu dikaitkan dengan dampak bisnis, yang diekspresikan melalui nilai kerugian bisnis. 


\subsection{Aspek SLA dan QoS}

a. Mendukung pemetaan parameter-parameter QoS.

Performa layanan yang telah di sepakati harus dapat diukur menggunakan parameter QoS. Karena itu, pengukuran kualitas layanan (misalnya availability layanan TI) harus dipecah lagi ke dalam pengukuran performa sumber daya pendukung fisik (misalnya nilai availability router). Hal ini perlu bagi penyedia layanan agar terhindar dari menjanjikan performa yang tidak mungkin dipenuhinya, misalnya karena keterbatasan kemampuan perangkat keras yang digunakan. Kerangka kerja SLM harus dapat memberi saran bagaimana cara memetakan secara vertikal parameter QoS antara layanan, sub layanan, dan sumber daya pendukungnya.

b. Mendukung pengukuran parameter QoS dan performa layanan

Parameter QoS harus dapat diukur. Pada kebanyakan kasus, unit yang diukur tidak sama dengan yang dispesifikasikan dalam SLA. Seringkali metrik yang digunakan oleh SLA merupakan gabungan beberapa metrik yang terukur secara fisik. Kerangka kerja SLA harus dapat mendukung pengukuran dan integrasi parameter-parameter SLA.

c. Pola (template) SLA atau aturan dalam merancang SLA

Aktivitas penting dalam SLM adalah membuat dokumen SLA serta menegosiasikannya dengan semua pelanggan. Kerangka kerja SLM harus mendukung tugas ini dengan menyediakan pola SLA yang mudah disesuaikan atau berupa panduan dalam merancang kontrak.

d. Dukungan kalkulasi dan pelaporan performa. Untuk mengkalkulasi dan melaporkan tingkat layanan yang dicapai pada pihakpihak yang terkait, SLM perlu memantau dan mengelola informasi tingkat layanan dan jumlah pelanggaran SLA yang terjadi. Kerangka kerja harus mampu menyediakan dukungan terhadap masalah ini. Pelaporan dan penentuan QoS membangun fondasi dalam menghitung tarif layanan.

e. Mendukung pengenaan tarif dan akuntansi berbasis SLA
Pembebanan pelanggan atas layanan yang digunakan tidak hanya terjadi pada perusahaan outsource. Pengenaan tarif menjadi penting bagi semua organisasi TI, termasuk pada organisasi penyedia layanan bagi pelanggan internal. Hal ini untuk mempertegas persepsi dari pelanggan internal mengenai perannya dari sisi bisnis. Karena itu masalah tarif harus sudah dibicarakan ketika menegosiasikan layanan dan merancang SLA, yang merupakan tanggungjawab dari fungsi SLM. Itulah sebabnya kerangka kerja SLM harus dapat memberikan panduan dalam mengintegrasikan tarif dan denda ke dalam SLA, misalnya dengan mencantumkannya pada pola SLA atau dalam proses pengembangan SLA.

\subsection{Aspek Umum}

a. Mendukung multi domain penyedia layanan.

Kerangka kerja SLM harus mampu mendukung kondisi yang melibatkan penyedia dari pihak ketiga dalam mengelola tingkat layanan.

b. Mendukung penyediaan layanan untuk berbagai pelanggan

Kerangka kerja SLM harus mampu memberi panduan dalam mengelola SLA yang berbeda bagi pelanggan yang berbeda secara efisien. Pembuatan modul-modul SLA serta pengembangan katalog layanan dapat menjadi solusi dalam memfasilitasi manajemen berbagai SLA tersebut.

c. Otomatisasi dan dukungan perangkat

Kerangka kerja SLM dapat menyediakan otomatisasi dan dukungan alat dengan cara memaksimalkan tingkat formalisasinya. Penggunaan bahasa pemodelan dan alat bantu misalnya XML atau UML dapat menolong dalam memperjelas kandungan kerangka kerja secara formal untuk memfasilitasi pengembangan dan penggunaan perangkat pendukung.

4. Analisa Best Practice Slm Cisco Menggunakan Kriteria Kelengkapan Thomas Schaaf

Pada bagian ini dipaparkan kajian terhadap best practice SLM dari CISCO 
berdasarkan kriteria pada aspek-aspek yang diusulkan oleh Thomas Schaaf [3].

\subsection{Aspek Manajemen}

a. Proses manajemen

Menurut Schaaf, "Suatu proses manajemen dikarakterisasikan melalui suatu rangkaian aktivitas beserta tanggung jawab yang jelas terhadap tiap langkahnya". CISCO memberikan panduan aktivitas SLM jaringan secara detil dalam tahap-tahap yang disertai beberapa contoh. Tiap tahap tersebut membutuhkan masukan (input) dan keluaran (output).

Meskipun CISCO tidak menjelaskan secara khusus mengenai proses manajemen, namun dengan merangkai seluruh tahap tersebut dalam suatu skenario best practice SLM menunjukkan bahwa best practice ini mendukung prinsip-prinsip proses manajemen.

Nilai $=$ cukup mendukung

b. Hubungan dan ketergantungan dengan disiplin manajemen yang lain.

Pada best practice SLM nya, CISCO hanya menyajikan panduan aktivitas dan teknik-teknik yang disarankan melalui sudut pandang penanggungjawab kualitas layanan jaringan, misalnya manajer SLM atau manajer jaringan.

Nilai $=$ tidak mendukung

c. Panduan penilaian manajemen

Untuk kriteria ini CISCO tampak mendukung penuh dengan menambahkan pembahasan secara khusus diluar 16 tahap yang diberikan, yaitu pada sub bahasan Indikator Performa SLM. Menurut CISCO, kesuksesan SLM diukur melalui: dokumentasi atau pendefinisian tingkat layanan, metrik performa indikator, dan pengkajian SLM. CISCO menjelaskannya secara lengkap apa yang harus dilakukan serta panduan bagaimana cara melakukannya.

$$
\text { Nilai }=\text { mendukung penuh }
$$

d. Keselarasan SLM dengan bisnis.

CISCO memandang SLM sebagai fungsi sentral dalam mengelola kualitas layanan melalui kesamaan persepsi antara penyedia dengan pelanggan. CISCO sangat menekankan untuk mengacu pada proses yang digerakkan oleh bisnis (business-driven process) hal ini ditunjukkan pada setiap langkah best practice nya.

Pada tahap pertama, CISCO menyebutkan perlu berdiskusi dengan bagian TI teknis ketika merencanakan suatu nilai target layanan. Kemudian CISCO menyarankan untuk mengundang perwakilan dari pelanggan yang dapat mewakili berbagai aspek bisnis untuk memperoleh gambaran kondisi kritis bisnis secara akurat. CISCO juga menganjurkan pendataan terhadap aplikasi-aplikasi yang digunakan oleh pelanggan untuk mendukung informasi akan kebutuhan bisnis disana. Bahkan dalam membangun kelompok kerja SLM, disarankan agar menyertakan perwakilan pelanggan yang memiliki pengaruh cukup besar dalam pengambilan keputusan, tujuannya agar komitmen terhadap kesepakatan (SLA) benar-benar terwujud.

Schaaf menambahkan, "suatu kerangka kerja SLM dapat dikatakan selaras dengan bisnis bila keputusan-keputusan penting yang mempunyai dampak bagi bisnis terekspresi melalui nilai rugi atau laba". Hal ini dipenuhi CISCO melalui matrik-matrik pedoman dukungan dalam bereaksi, baik secara reaktif maupun pro aktif, yang mengacu pada klasifikasi dampak gangguan terhadap bisnis. Contohnya adalah penggunaan IUM (impacted user minutes) sebagai metode pengukuran pada tahap pendefinisian availability.

Nilai best practice CISCO pada kriteria ini adalah mendukung, karena tidak membahas secara khusus arti penting keselarasan SLM terhadap bisnis melainkan meleburnya berupa panduan yang merupakan perwujudan dari keselarasan SLM dengan bisnis.

Nilai $=$ cukup mendukung

\subsection{Aspek SLA dan QoS}

a. Mendukung pemetaan parameter-parameter QoS.

Penjelasan khusus mengenai pemetaan parameter-parameter QoS belum diberikan oleh CISCO. Namun kriteria ini dipenuhi melalui panduannya pada enam tahap pendefinisian tingkat layanan. Misalnya, QoS 
dinyatakan berdasarkan parameter yang dipahami oleh pengguna, namun pengukurannya dilakukan secara langsung terhadap sumber daya fisik antara lain perangkat keras, perangkat lunak, listrik, dan sebagainya. Dengan begitu terjalin pemetaan parameter-parameter QoS terhadap sumber daya yang mendukungnya.

Nilai = cukup mendukung

b. Mendukung pengukuran parameter QoS dan performa layanan.

CISCO menekankan bahwa parameter tingkat layanan yang akan disampaikan harus benar-benar dapat diukur (measureable) dan dipadukan (agregat), misalnya dengan parameter dari pihak ketiga. Hal ini ditunjukkan dengan persaratan untuk memahami pengetahuan teknis akan perangkat yang digunakan serta perangkat lunak pengukuran (sebagai antar muka) yang dimiliki atau harus dibeli.

Matrik-matrik yang disampaikan mulai tahap kesatu hingga keenam dapat digunakan sebagai pola atau dasar pengukuran parameter QoS dan performa layanan. Termasuk panduan dalam mengatur pengklasifikasian ataupun dalam pemilihan metode pengukuran yang ideal.

Nilai $=$ mendukung penuh

c. Pola (template) SLA atau aturan dalam merancang SLA.

CISCO memberi gambaran prosedur umum dalam membangun dan mengelola SLA jaringan secara terpadu dalam 16 langkah. Bagian pertama adalah untuk mendalami kejelasan tingkat layanan. Kemudian dilanjutkan bagian kedua yaitu mengimplementasikan SLA berdasarkan hasil analisis sebelumnya. Selain memberi penjelasan lengkap mengenai metode reaktif dan proaktif bagi SLA, CISCO juga menyertakan contoh format SLA untuk jaringan yang dapat digunakan sebagai template acuan.

Nilai $=$ mendukung penuh

d. Dukungan kalkulasi dan pelaporan performa.

Panduan kalkulasi dan pelaporan diberikan berupa penjelasan, perumusan, dan contoh. Sebagai contoh pada langkah kedua yaitu perancangan kebutuhan availability, disitu diberikan rumus yang dapat digunakan, contoh kasus dan analisa berdasarkan kasus tersebut.

CISCO menekankan lima prinsip untuk menjaga performa SLA yaitu parameter yang digunakan harus dapat diukur, penanganan permasalahan sebaiknya berupa reaksi dan proaksi, melakukan pengumpulan data-data performa, pengkajian mingguan terhadap data performa tersebut, serta memperbaiki dan memperbarui SLA sesuai perkembangan situasi.

Nilai $=$ mendukung penuh

e. Mendukung pengenaan tarif dan akuntansi berbasis SLA.

Best practice CISCO menyampaikan bahwa pelanggan sebaiknya mendapat informasi dan memahami layanan yang diminta, sehingga dapat menyepakati biayabiaya yang terkait dengannya. Biaya tersebut terutama menyangkut tambahan biaya untuk penambahan kualitas layanan, dan penghitungan denda/ penalti. Namun CISCO tidak memberi panduan bagaimana penghitungan biaya tersebut dalam basis SLA.

Misalnya penghitungan penalti berdasarkan penurunan kualitas layanan yang dapat terpantau langsung oleh pengguna. Atau data penambahan biaya bagi pelanggan yang ingin meningkatkan kualitas layanan.

Namun sebenarnya tahapan yang diberikan CISCO sudah memberi jalan dalam mendukung pengenaan tarif dan akuntansi berbasis SLA, misalnya penggunaan parameter dalam bahasa bisnis agar dapat disandingkan dengan biaya yang terkait dengannya sehingga dapat dipahami oleh kedua belah pihak.

$$
\text { Nilai }=\text { kurang mendukung }
$$

\subsection{Aspek Umum}

a. Mendukung multi domain penyedia layanan.

Cakupan yang dibahas dalam best practice ini hanya antara satu penyedia layanan dengan pelanggan-pelanggannya. Tidak membahas posisi dan peran suatu penyedia layanan sebagai pelanggan dari penyedia yang lain, atau yang biasanya disebut sebagai pihak ketiga. 
Nilai $=$ tidak mendukung

b. Mendukung penyediaan layanan untuk berbagai pelanggan.

CISCO sangat memperhatikan keragaman kebutuhan pelanggan. Pengelolaan keragaman ini dikenali melalui identifikasi langsung terhadap pihak yang terkait dan juga melalui identifikasi aplikasi-aplikasi yang digunakan. CISCO juga memberi contoh klasifikasi kualitas layanan misalnya premium, gold, dan bronze sehingga pelanggan dapat memilih sesuai kebutuhan dan anggaran yang dimilikinya.

Namun CISCO belum menjelaskan bagaimana menerapkan konsep modularisasi format SLA dan katalog layanan agar dapat mendukung pengelolaan berbagai SLA seperti yang disarankan oleh Schaaf.

Nilai $=$ kurang mendukung

c. Otomatisasi dan dukungan perangkat.

Panduan dari CISCO menyarankan untuk memanfaatkan otomatisasi dan dukungan perangkat dalam mengimplementasikan SLM. Namun tidak menjelaskan bagaiman cara tersebut dapat dilakukan. CISCO hanya menyampaikan bahwa perangkatperangkatnya telah menyediakan fasilitas otomatisasi dan dukungan bagi SLM, antara lain interface XML, agen inteligen tingkat layanan, probe, server arsip SLM, serta perangkat lunak manajemen SLM.

Nilai $=$ kurang mendukung

Tabel 1. Penilaian Best Practice SLM CISCO Menggunakan Kriteria Kelengkapan Kerangka Kerja SLM Dari Thomas Schaaf.

\begin{tabular}{|c|c|c|c|}
\hline Kelompok & Kode & Kriteria kebutuhan & CISCO \\
\hline \multirow{4}{*}{$\begin{array}{c}\text { Aspek } \\
\text { Manajemen }\end{array}$} & M1 & Proses manajemen & $\sqrt{ }$ \\
\hline & M2 & $\begin{array}{l}\text { Hubungan dan ketergantungan dengan disiplin manajemen } \\
\text { yang lain }\end{array}$ & $\mathrm{X}$ \\
\hline & M3 & Panduan penilaian manajemen & $\sqrt{ } \sqrt{ }$ \\
\hline & M4 & Keselarasan SLM dengan bisnis & $\sqrt{ }$ \\
\hline \multirow{5}{*}{$\begin{array}{l}\text { Aspek SLA dan } \\
\text { QoS }\end{array}$} & $\mathrm{S} 1$ & Mendukung pemetaan parameter-parameter QoS & $\sqrt{ }$ \\
\hline & $\mathrm{S} 2$ & $\begin{array}{l}\text { Mendukung pengukuran parameter QoS dan performa } \\
\text { layanan }\end{array}$ & $\sqrt{ } \sqrt{ }$ \\
\hline & $\mathrm{S} 3$ & Pola (template) SLA atau aturan dalam merancang SLA & $\sqrt{ } \sqrt{ }$ \\
\hline & $\mathrm{S} 4$ & Dukungan kalkulasi dan pelaporan performa & $\sqrt{ } \sqrt{ }$ \\
\hline & S5 & Mendukung pengenaan biaya dan akuntansi berbasis SLA & $(\sqrt{ })$ \\
\hline \multirow{3}{*}{ Aspek Umum } & U1 & Mendukung kondisi multi domain penyedia layanan & $\mathrm{X}$ \\
\hline & $\mathrm{U} 2$ & Mendukung penyediaan layanan untuk berbagai pelanggan & $(\sqrt{ })$ \\
\hline & U3 & Otomatisasi dan dukungan perangkat & $(\sqrt{ })$ \\
\hline
\end{tabular}

Dengan sedikit modifikasi dari teknik penilaian yang digunakan oleh Thomas Schaaf, berikut ini penjelasan untuk nilai-nilai yang diberikan pada tabel 1:

Mendukung penuh $=\sqrt{ }$, Artinya bila kriteria yang dimaksud merupakan ketentuan yang sudah dijalankan, dan dinyatakan secara eksplisit dengan disertai penjelasan apa yang perlu dilakukan, bagaimana cara melakukannya dan disertai contoh.

Cukup mendukung $=\sqrt{ }$, Artinya bila kriteria yang dimaksud merupakan ketentuan yang telah dipenuhi namun belum lengkap atau tidak dijelaskan secara terperinci. Misalnya berupa prinsip-prinsip yang menjadi landasan proses 
SLM secara keseluruhan namun tidak dijelaskan secara khusus arti penting prinsip tersebut.

Kurang mendukung $=(\sqrt{ })$, Artinya bila kriteria yang dimaksud baru sebatas saran agar dipenuhi, disertai penjelasan manfaatnya.

Tidak mendukung $=\mathrm{X}$, Artinya bila kriteria yang dimaksud tidak diulas sama sekali.

\section{Hasil Dan Usulan Terhadap Best Practice SIm Dari Cisco}

Hasil analisa beserta usulan pada bagian yang kurang dan tidak mendapat dukungan (mengacu matriks pada tabel 1) disajikan sebagai berikut:

\subsection{Area yang mendapat dukungan penuh (M3, S2, S3, S4)}

Kriteria-kriteria yang mendapat dukungan penuh melalui best practice CISCO adalah area yang sangat dekat dengan unsur teknis, yaitu pendefinisian, pemantauan, penghitungan, pengukuran, dan pelaporan parameter-parameter yang diperlukan. Termasuk pula struktur dan format SLA berdasarkan hasil analisis teknis tersebut.

\subsection{Area yang mendapat cukup dukungan (M1, M4, S1)}

Ada tiga kriteria yang mendapat cukup dukungan dari best practice CISCO, kriteriakriteria tersebut merupakan prinsip-prinsip penting yang melandasi best practice SLM CISCO.

\subsection{Area yang kurang mendapat dukungan (S5, U2, U3)}

Pada area ini CISCO hanya menyampaikan arti pentingnya serta menyarankan untuk mengimplementasikannya, namun tidak membahas lebih jauh.

Karena itu untuk melengkapinya dapat ditambahkan usulan sebagai berikut:

a. Dukungan pengenaan biaya dan akuntansi berbasis SLA

Schaaf mengatakan, hingga saat ini belum ada solusi untuk akuntansi berbasis SLA [7]. Untuk sedikit melengkapi kriteria ini maka sebaiknya organisasi mengintegrasikan penghitungan biaya dan penalti ke dalam dokumen SLA. b. Dukungan penyediaan layanan untuk berbagai pelanggan

Pengelolaan multiple SLA untuk berbagai pelanggan mengindikasikan kebutuhan untuk membangun SLA yang fleksible dan mudah menyesuaikan terhadap perkembangan situasi dan kondisi. Karena itu penulis mengarahkan untuk mengacu pada ITIL [6] dalam penggunaan katalog layanan dan struktur SLA yang bertingkat.

c. Otomatisasi dan dukungan perangkat

Bila kita tidak dapat mengukur tingkat layanan secara akurat, maka kita tidak akan dapat memperbaikinya [1]. Selain itu, kerangka kerja SLM membutuhkan metode untuk mendapatkan dukungan perangkat yang tidak tergantung pada vendor tertentu.

Penulis merujuk pada Schaaf dan Brenner [8] yang memberikan solusi dalam mengatasi permasalahan ini. Mereka mengusulkan pendekatan ala model driven architecture (MDA) untuk memperoleh model yang platform-independent yang dapat ditransformasikan kedalam perangkat lunak platform-specific.

\subsection{Area yang tidak didukung (M2, U1)}

Solusi untuk area yang tidak didukung oleh best practice CISCO dapat diberikan dengan mengacu dari referensi-referensi lain yang mampu melengkapinya. Berikut ini uraiannya:

a. Hubungan dan ketergantungan dengan disiplin manajemen yang lain.

Untuk organisasi penyedia layanan yang kecil masih memungkinkan untuk mengerjakan semua disiplin manajemen layanan tanpa pembagian yang jelas. Namun untuk kondisi yang ideal, ITIL menyarankan untuk membangun sepuluh proses manajemen serta satu fungsi yaitu service desk.

Penulis mengusulkan panduan ITIL [6] mengenai keterkaitan antar proses, dan keterkaitan SLM dengan proses yang lain sebagai referensi yang sesuai dengan kondisi ini.

b. Mendukung kondisi multi domain penyedia layanan

Penulis mengusulkan model layanan MNM [4] untuk memberi gambaran 
mengenai kondisi multidomain. Dengan model tersebut kita dapat melihat dari sudut pandang penyedia layanan, yaitu dalam realization view, yang dapat digunakan untuk mengidentifikasikan kebutuhan sub-layanan, sumber daya, dan fungsionalitas manajemen suatu penyedia layanan dalam mengkaji perannya sebagai pelanggan dari pihak ketiga.

\section{Penutup}

Berdasarkan analisa menggunakan kriteria kelengkapan dari Thomas Schaaf ditemui bahwa best practice SLM CISCO memiliki kekuatan pada aspek QoS dan SLA, yang ditandai melalui kejelasannya dalam menguraikan aspek ini secara detil dan disertai contoh-contoh.

Pada aspek manajemen, CISCO memberikan panduan yang cukup lengkap namun tidak secara khusus membahasnya, melainkan memberikan prinsip-prinsip yang telah siap pakai khususnya bagi manajer SLM dalam mengambil langkah dan kebijakan.

Sedangkan pada aspek umum, CISCO belum banyak mendukung terutama karena tidak menjelaskan dukungan terhadap multi domain aktor-aktornya serta belum memberi solusi tentang cara agar proses SLM yang diterapkan dapat terotomatisasi.

Beberapa saran dan usulan yang penulis berikan adalah :

- mengintegrasikan penghitungan biaya dan penalti ke dalam dokumen SLA.

- menggunakan katalog layanan dan struktur SLA yang bertingkat untuk mendukung penyediaan layanan untuk berbagai pelanggan.

- pendekatan model driven architecture (MDA) untuk memperoleh model yang platform-independent yang dapat ditransformasikan kedalam perangkat lunak platform-specific dapat digunakan agar otomatisasi dan dukungan perangkat tidak bergantung pada vendor tertentu

- mengadaptasikan hubungan dan ketergantungan SLM terhadap disiplin manajemen yang lain dengan merujuk ITIL.

- menggunakan model dasar layanan dari MNM untuk memberi gambaran kondisi multidomain penyedia layanan.
- Harapan penulis rekomendasi-rekomendasi tersebut dapat digunakan sebagai pelengkap untuk mendampingi best practice SLM dari CISCO.

\section{Daftar Pustaka}

[1] Brazao, Anne, "Improve Service Levels with Meaningful Measurement", Communications News, Proquest Telecommunication. Halaman 88, 2000.

[2] CISCO, "Successful Implementation Strategies for Service-Level Management". CISCO System, 2000. Dapat diunduh di : http://dpnm.postech.ac.kr/slamgmt/refpapers/031\%20Successful Imple mentation_Strategies_for_Service_Level_M anagement.pdf

[3] CISCO, "Service Level Management: Best practice White Paper". CISCO System, 2005. Dapat diakses melalui : http://www.CISCO.com/en/US/tech/tk869/t k769/technologies white paper09186a0080 11e783.shtml

[4] M. Garschhammer et al. "Towards Generic Service Management Concepts". A Service Model Based Approach. Proceedings of the $7^{\text {th }}$ IEEE/IFIP International Symposium on Integrated Network Management (IM 2001), Seattle, Washington USA, IEEE Publishing, May 2001. Dapat diunduh di : http://www.nm.ifi.lmu.de/pub/Publikatione n/smtf01/PDF-Version/smtf01.pdf

[5] Office of Government Commerce (OGC), editor, "Planning to Implement Service Management", The Stationary Office (TSO), 2002.

[6] Office of Government Commerce (OGC), editor. "Service Delivery book V 2.0", The Stationary Office (TSO), 2003.

[7] Schaaf, Thomas. "Frameworks for Business-driven Service Level Management". A Criteria-based Comparison of ITIL and NGOSS. 2007. In Proceedings $2^{\text {nd }}$ IEEE/IFIP International workshop on Business-Driven IT Management. (BDIM 2007), 2007. Dapat diunduh di :

http://www.nm.ifi.lmu.de/pub/Publikatione n/scha07/PDF-Version/scha07.pdf 
[8] Schaaf, Thomas et al. "On Tool Support for Service Level Management: From Requirements to System Specification". In Proceeding $3^{\text {rd }}$ IEEE/IFIP International
Workshop on Business-Driven IT Management, 2008. Dapat diunduh di: http://www.nm.ifi.lmu.de/pub/Publikatione n/brsc08/PDF-Version/brsc08.pdf 